\title{
Editorial
}

\section{Music Education in Africa}

Coming from Botswana, South Africa, Zimbabwe, Ghana and Kenya, the papers in this Special Issue on Music Education in Africa cannot portray a definitive story of music education in all 54 sovereign states in the Continent, but as a first step towards understanding what matters in this region of the world, the range of topics in this issue provides us with a focal point for dialogue.

Some of the concerns we see in the papers appear universal - such as the challenge of access and participation for disadvantaged or remote communities, the need for rigorous preparation for student teachers at pre-service, the desire to provide more targeted supports for experienced teachers through in-service and the need for advocacy at all levels, from local community to national policy level. Matching student teachers with carefully selected, expert teachers in a mentoring relationship holds promise of careful nurturing for the former and renewal for the latter. Yet, we know from our research and experience, that tackling any one of these issues requires taking a rather long view. Change, whether at local or system level, requires decades of advocacy, years of investment and substantial follow-through to sustain impact. Legislative frameworks are also useful. Meanwhile, as those of us in more privileged environments fuss about issues of, say, access to superior quality musical instruments, rooms with excellent acoustics, or tiny interruptions in our wi-fi signals, we are likely to forget that our colleagues leading change in some remote parts of Africa may not even have access to electricity, or are entirely dependent on infrequent public transport just to attend a professional development workshop. Moreover, hunger and war loom large for far too many.

Challenges are not simply material though. Matters of cultural sensitivity in diverse communities with high immigrant populations and multilingual traditions stretch our understanding of second language learning. One cannot help thinking that policy makers may have been well intentioned in drawing from existing music curricula in Western countries in their efforts to align curricula in African states with their counterparts elsewhere. But as much of the research in this issue reveals, the indigenous music struggles to find its place in the core music curriculum where this has occurred. As Otchere (this issue) remarks, it is not that Western music is bad per se, it is just that there are very rich traditions within African countries that should be entitled to their own cultural and educational attention.

Musical literacy, and all its manifestations in digital format, provides a lever to further musical exploration and independence. For a Western child, the avenues to music literacy may come about in a number of ways and through a range of tools or instructional settings. Music literacy can provide the child with skills to explore and record music on his or her own and of her or his own making. Ultimately, it may mean the passing of an examination, successfully auditioning for a prestigious orchestra, or recording original music with a group of friends. For a child in an African country, musical literacy is perhaps more important in that it provides a pathway to capturing the huge diversity of musical arts that are found across the continent. The wide array of instruments, drums, use of vocalisation techniques 
and polyrhythms open up to immense musical possibilities - and that is without counting the myriad musical styles and traditions of Africa that have gone on to influence music making in North America especially.

We have much to learn from the beautiful, diverse and often mesmerising music from across Africa and from our colleagues whose dedication and interest illuminates many possibilities for further research, practice, professional learning and reflection. Action research in these contexts is far from being a desk exercise but calls for work that has the potential to engage researchers in action-oriented, critical and emancipatory inquiry (Carr \& Kemmis, 1986) and that benefits participants and researchers alike. Deeper understandings of praxis (Freire, 1970) await our attention together with an impetus towards an activist oriented profession (Sachs, 2003).

As editors, we have tried to strike a balance between our usual interventions and maintaining authentic African voices, allowing the authors to shine through in their own words and phraseology. Again, we caution against generalising from the research examples of these countries to the whole continent as the authors emphasise the specificity of their contexts, settings and research orientations. What comes across most strongly in the papers, though, is a palpable sense of resilience and commitment to music education even in the most adverse of circumstances.

We open with Sheelagh Chadwick's paper on action research with music teachers in Botswana. This article describes initial explorations into action research with music teachers in Botswana and outlines the possibilities and potential for change - both in teachers' views of their work, and for approaches that bring students' knowledge and skills to the forefront of music classrooms. Researcher mistakes and learning are also explored, demonstrating the need for ongoing critical reflection and adaptation in this complex setting.

Sithulisiwe Bhebhe, Tawanda Runhare and Ratau John Monobe explore the topic of training music teachers through distance learning. Related to this, is how student teachers experience mentoring in their teaching practice/school placement in a teacher training college in Zimbabwe. Matching the student's specialism in music with a teacher with interest and expertise in music proves particularly challenging and gives rise to thoughtful reflections from the lecturers, teaching practice coordinators, classroom teachers and student teachers alike.

In exploring the implementation of the primary curriculum in music in South Africa, Eurika Jansen van Vuuren and Caroline van Nierkerk draw attention to teachers' reluctance to engage with what is termed Life Skills in South Africa (Dance, Drama, Music, Visual Art, Physical Education and Personal and Social Well-being) and Creative Arts (Dance, Drama, Music, Visual Art). Given the lack of investment in the professional development of teachers, it is not surprising that their study uncovers many challenges for generalist educators. Similar to their colleagues in Zimbabwe, they identify student mentoring as a possible vehicle for supporting professional learning in context.

Acknowledging the historical context of music in Ghanaian school programmes, Eric Debrah Otchere explores the higher education curriculum for evidence of Ghanaian music in the undergraduate programmes on offer. If, as he suggests, the process of music education is also a process of enculturation, then the indigenous music of Ghana is not afforded the status that it might deserve in its own land where Western music dominates the courses available to students in some higher education institutions. 
Taking a Kenyan perspective, Emily Achieng' Akuno examines the nature of song teaching in primary schools. Her description of the cultural context of each song is illuminating and highlights the potential of songs to serve as instructional material across a broad range of culturally appropriate social contexts. However, the disconnect between this richness of practice, outside of school as it were, and the potential to contribute to learning within school, is stark. The paper again calls for greater attunement between curriculum aspirations and cultural relevance for young learners in music.

Finally, Alethea de Villiers presents a case study from South Africa that sought to transform music education. Her commitment to change and improvement for teachers is demonstrated in the design and implementation of a continuing professional development programme for teachers that was presented in challenging teaching circumstances. The spirit of curriculum renewal, located in democratic values, inspires this professional development initiative and leaves us with the hope that change can be constructive and meaningful given time, dedication and support.

REGINA MURPHY and MARTIN FAUTLEY

BJME Co-editors

\section{References}

CARR, W. \& KEMMIS, S. (1986) Becoming Critical: Education, Knowledge, and Action Research. London: Falmer.

FREIRE, P. (1970) Pedagogy of the Oppressed. New York, NY: Continuum.

SACHS, J. (2003) The Activist Teaching Profession. Buckingham: Open University Press. 